\title{
Michel Raimond, Le monde moderne vu par les écrivains (1900-1950)
}

\section{René Corona}

\section{Q OpenEdition}

1 Journals

\section{Edizione digitale}

URL: https://journals.openedition.org/studifrancesi/21657

DOI: 10.4000/studifrancesi.21657

ISSN: 2421-5856

\section{Editore}

Rosenberg \& Sellier

\section{Edizione cartacea}

Data di pubblicazione: 1 décembre 2019

Paginazione: 605

ISSN: 0039-2944

\section{Notizia bibliografica digitale}

René Corona, «Michel Raimond, Le monde moderne vu par les écrivains (1900-1950)», Studi Francesi

[Online], 189 (LXIII | III) | 2019, online dal 01 mars 2020, consultato il 11 novembre 2021. URL: http:// journals.openedition.org/studifrancesi/21657 ; DOI: https://doi.org/10.4000/studifrancesi.21657

Questo documento è stato generato automaticamente il 11 novembre 2021.

\section{(c) (i) (9)}

Studi Francesi è distribuita con Licenza Creative Commons Attribuzione - Non commerciale - Non opere derivate 4.0 Internazionale. 


\title{
Michel Raimond, Le monde moderne vu par les écrivains (1900-1950)
}

\author{
René Corona
}

\section{NOTIZIA}

Michel Raimond, Le monde moderne vu par les écrivains (1900-1950), édition de J.-M.

Raimond et V. Rambaud, Paris, Classiques Garnier, 2019, 216 pp.

1 Con questo libro postumo, curato dal figlio dell'autore e da un suo discepolo e amico, Michel Raimond, già noto per il suo La crise du roman. Des lendemains du naturalisme aux années vingt, ci presenta un periodo storico connotato dalla crisi dei valori e filtrato attraverso il pensiero e l'opera di intellettuali e scrittori dall'inizio del secolo fino agli anni Cinquanta. In sintesi, si parte dal pensiero socialista e cristiano di Charles Péguy per giungere a Giono e alla sua visione di una vita naturale; in entrambi i casi l'obiettivo finale è la critica del mondo moderno (che poi è anche il titolo di un capitolo). Nell'opera di Péguy si situano i prodromi della crisi socio-politica della società francese e in parte di quella europea che si tradurrà nella Grande Guerre. Raimond si concentra su quelle menti eccelse che hanno determinato l'avanzare dello spirito critico; intellettuali, spesso dimenticati dalle storie letterarie odierne, che tuttavia hanno svolto un ruolo preponderante, all'inizio del secolo, nel forgiare le coscienze. Essi hanno tentato di dare risposte all'emergenza della crisi che inevitabilmente condurrà la Francia al primo conflitto mondiale e poi, in seguito a un dopoguerra inquieto e denso di tensioni sociali, verso un secondo conflitto ancora più drammatico.

2 Nell'introduzione l'autore segnala che i germi di questa crisi della società e dei suoi valori è già presente nel pensiero intransigente e reazionario, conservatore e monarchico di Bonald e de Maistre fino a Maurras e Barrès. Questi pensatori hanno in comune, con i trentenni della generazione del primo dopoguerra, un sentimento di ribellione nei confronti della modernità, della macchina, dell'industria, e un forte sentimento passatista che fa sì che rimpiangano un mondo più giusto, al centro del 
quale stava l'uomo e non l'automatismo. Se fino al primo conflitto mondiale vi erano ancora tracce di una speranza nel futuro, con lo sconquasso bellico arriviamo a uno choc delle coscienze. Michel Raimond scopre una visione catastrofica, comune a molti, e vediamo apparire spesso nei testi la parola "apocalisse". Siano essi pensatori della rivista "Esprit" come Mounier, liberali e cristiani chiamati non-conformistes come Alexandre Mac, Maulnier, Aron, o de Rougemont, borghesi illuminati come Halévy e Berl, pensatori attratti dall'esoterismo e dall'Oriente come Guénon o sostenitori di un ritorno alla spiritualità come Maritain, spiriti liberi e di sinistra come Bloch, Guéhenno, ma anche il primo Drieu la Rochelle, Suarès, Rolland e la rivista "Europe", comunisti come Nizan e Aragon, tutti hanno orrore del mondo moderno che priva l'uomo della propria centralità, dei misfatti dell'industrializzazione, di una politica assoggettata all'economia e al mercato. Scrittori come Duhamel, Céline e Bernanos descrivono l'apocalisse prima attraverso la mattanza della guerra e poi tramite la visione della società americana senz'anima. Un capitolo, il quarto, analizza il malessere del mondo moderno, una volta scoperto che capitalismo o comunismo si sono piegati al cospetto del dio denaro e della macchina; infine, con il crollo bancario del 1929, lo sgomento è totale. Questo permette un ritorno delle coscienze verso la ricerca di una spiritualità e anche uno sguardo verso altre spiritualità in Oriente. Oltre ai pensatori, Raimond legge anche le opere degli scrittori, principalmente i romanzi di Aragon e il suo "mondo del reale", di Paul Morand e le sue macchine ultraveloci, di Jules Romains "dottore in scienze sociali", del modernista Cendrars e di Giono, fautore di un ritorno alla natura e a una vita semplice. L'A. mostra, basandosi anche su un'analisi della poesia di quel periodo, come molti di questi scrittori, i quali da giovani hanno celebrato il mondo moderno, in età avanzata abbiano fatto poi un passo indietro, preoccupandosi delle conseguenze nefaste di questa modernità. Sebbene, nelle sue conclusioni, Raimond sostenga che l'epoca analizzata fosse densa di drammaticità, è pur vero che si possono riscontrare analogie, come fanno notare i due curatori, con la nostra epoca odierna e ciò apre, dopo questa lettura stimolante, nuove prospettive di discussione. 